\title{
Quality Indicators of Special Products with Target Functional Properties
}

\author{
Evgeniya Yu. Lobach \\ Kemerovo State University \\ Candidate of Sciences (Engineering), associate professor \\ Department of Marketing and Business-communications \\ Russian Federation, Kemerovo \\ Lobach_evgenia@mail.ru
}

\author{
Alexander N. Avstrievskikh \\ ArtLife Company, \\ Doctor of Sciences (Engineering), professor \\ Russian Federation, Tomsk
}

\author{
Marina G. Kurbanova \\ Kemerovo State Agricultural Institute \\ Doctor of Sciences (Engineering) \\ Russian Federation, Kemerovo
}

\author{
Valeriy M. Poznyakovskiy \\ Kemerovo State Agricultural Institute \\ Honored Science Worker of the RF, Doctor of Sciences \\ (Biology), professor, head of Scientific and Educational \\ Center Processing of agricultural stock and food \\ technologies, Head of backbone department Food industry \\ and functional nutrition, Russian Federation, Kemerovo
}

\begin{abstract}
The work develops the formulation and technology for probiotic candies enriched with bifidobacteria (bifidobacterium adolescentis) and lactobacteria (lactobacillus plantarum and lactobacillus acidophilus) in respective amount of $(C F U / 100 \mathrm{~g})$ at least $5.0 * 109$ and $5.0 * 108$. The feature of the technology is the application of microencaspulation providing the stability of probitotics in aggressive medium of stomach, preservation of their properties, survival and activation with transportation to the location of living activities. The biologically active components of the formula demonstrate high stability on the example of vitamin $C$. The quality and safety indicators were studied along with organoleptic (shape, exterior, color, taste and odor), physicochemical (average mass of one candy, moist mass fraction), sanitary and hygienic (mesophile aerobic and facultatively anaerobic microorganisms, pathogenic, including salmonela, coliforms, yeast fungi, moulds), sanitary and toxicological (lead, arsenic, cadmium, mercury, cesium-137, strontium-90), which allowed determining the nutritional value, functional destination and sell-by date of developed products: mass fraction of ascorbic acid, $\mathrm{mg} / 100 \mathrm{~g}-900$; content of bifidobacteria (bifidobacterium adolescentis) (for Bifidopan candies) CFU/100g, not less than $5.0 * 109$; lactobactera (lactobacillus plantarum and lactobacillus acidophilus) (for Laktopan candies) CFU/100 g, not less than $5.0 * 108$; fats, g/100g (averaged data) - 20.5; carbohydrates, $\mathrm{g} / 100 \mathrm{~g}$ (averaged data) 67.3. Energy value is $454 \mathrm{kcal}$. Sell-by date is 1 year at the temperature not higher than $25{ }^{\circ} \mathrm{C}$ and relative air humidity of $70 \%$.
\end{abstract}

Special products were tested under conditions of production, certified within the international requirements such as ISO 9001 and GMP rules.

Keywords-probiotic product, formulation, bifido- and lactobacteria, technology, controllable quality indicators, functional destination

\section{INTRODUCTION}

The development of special products, including biologically active additives (BAA) is one of the most affordable and effective means for correcting nutrition and health of contemporary man, which is logical continuation of the work of Nobel laureate I.P. Pavlov in the field of understanding of the role of food in formation of the physiology of future [3, 6-8].

This vector of nutritiology is of both theoretical and practical significance within the realization of the action plan in the sphere of alimentary products and nutrition of European region of WHO [2].

A particular attention is paid to biological aspects of the problem, taking into the account the role of microorganisms in provision of necessary balance of microflora of gastrointestinal tract. In this connection, the problems of developing new types of probiotic products are high on the agenda with due consideration of the spread of diseases connected with a disbalance of gut microflora that takes part in many vital processes in the organism $[4,5]$. One of such pathologies is dysbacteriosis, i.e. disturbance of the biotic balance between pathogenic and physiological (healthful) microflora of the organism. Dysbacteriosis can lead to the inability of the gastrointestinal tract to digest food appropriately. It deteriorates the absorption of vitamins and mineral substances, decreases the protective function of the intestine against pathogenic bacteria and invasion of toxins into blood. This promotes diseases in all organism systems: digestive, immune, hemapoietic, urinogenital, respiratory, cardiovascular, neural, 
bone and muscle. The prophylactic measures for improving health of gut microflora, supporting and normalizing its condition are the necessary conditions for proper immunity, improved resistivity of the organism to infections and regular metabolism.

\section{OBJECTS AND METHODS}

We have developed a new group of probiotic candies enriched by bifido- and lactobacteria. The objects of investigation were initial components of the formulation, test and production samples. representative groups of people with dysbacteriosis of 2 nd stage. We apply standard and special methods to study the quality and safety of special products as per the requirements of acting regulations [8].

\section{RESULTS AND DISCUSSION}

Considering biochemical and pharmacological characteristics of input components, we have scientifically justified the quantitative and qualitative formulation (Table 1).

TABLE 1. FORMULATION OF PROBIOTIC CANDIES ENRICHED BY BIFIDO- AND LACTOBACTERIA

\begin{tabular}{|c|c|c|}
\hline Name of components & $\begin{array}{l}\text { Bifidopan } \\
{[\mathrm{g} / \mathbf{1 0 0 g}]}\end{array}$ & $\begin{array}{l}\text { Lactopan } \\
{[\mathrm{g} / \mathbf{1 0 0 g}]}\end{array}$ \\
\hline Imitation milk & $\begin{array}{l}75.984 \\
(759.84)^{*}\end{array}$ & $\begin{array}{l}764.26 \\
(76.426)^{*}\end{array}$ \\
\hline Crystalline fructose & $8.0(80)$ & $8.0(80)$ \\
\hline Bifidogum $\left(1 * 10^{10} \mathrm{CFU} / \mathrm{g}\right)$ & $0.5(5.0)$ & \\
\hline $\begin{array}{l}\text { Lactogum }\left(1 * 10^{10} \mathrm{CFU} / \mathrm{g}\right) / \\
\text { Acidogum }\left(1 * 10^{10} \mathrm{CFU} / \mathrm{g}\right)\end{array}$ & & $0.25(0.025)$ \\
\hline Topinambour root powder & $5.0(50)$ & $5.0(50)$ \\
\hline Inulin Fibrulin XL & $4.0(40)$ & $4.0(40)$ \\
\hline Ascorbic acid & $0.9(9.0)$ & $0.9(9.0)$ \\
\hline $\begin{array}{l}\text { Flavor identical to natural: apple or } \\
\text { raspberry / (strawberry, orange) }\end{array}$ & $0.5(5.0)$ & $0.5(5.0)$ \\
\hline Stevioside & $0.1(1.0)$ & $0.1(1.0)$ \\
\hline $\begin{array}{l}\text { Natural color, chlorophyll or carmine } \\
0002\end{array}$ & $0.024(0.16)$ & $0.024(0.16)$ \\
\hline Final mass of candy shell & - (950) & $-(950)$ \\
\hline Acacia gum & $0.5(5.0)$ & $0.5(5.0)$ \\
\hline Maltitol & $4.5(45.0)$ & $4.5(45.0)$ \\
\hline Total candy mass with cover & $1000(100)$ & $1000(100)$ \\
\hline
\end{tabular}

The work has developed the formulation and technology for probiotic candies enriched with bifidobacteria (bifidobacterium adolescentis) and lactobacteria (lactobacillus plantarum and lactobacillus acidophilus) in respective amount of (CFU/100 g) at least $5.0 * 10^{9}$ and $5.0 * 10^{8}$.
The technological process includes the following production stages:

- Preparation of initial products (screening, 0.5-mm mesh Bifilogum, Lactogum. Mesh no. 22);

- Weighting, fixing quantitative and qualitative composition;

- Mixing the formulation components for 40-50 minutes, weighting and fixing;

- Tableting: die diameter is $16 \mathrm{~mm}$, average candy mass is $0.95 \mathrm{~g} \pm 10 \%$;

- Maltitol syrup: fraction of solids is $68-72 \%$;

- Dedusting;

- Coating by shell up to the average mass of $1.0 \mathrm{~g} \pm 10 \%$;

- Holding for $5-10$ hours at $25^{\circ} \mathrm{C}$;

- Storage: one year at the temperature not higher than 25 ${ }^{\circ} \mathrm{C}$ and relative air humidity not higher than $70 \%$.

The development of the probiotic products used the microencaspulation technology. The bacteria are confined in a thin microcapsule coated by protective biopolymeric coating providing stability in acidic medium of stomach and other effects. The core of the microcapsule is the framework from natural fibers that is the nutritional medium for the bacteria. This preserves the properties of the microorganisms for long time, including the transportation to the spot of their living activities. Vitamins and prebiotic substances, being in optimal dosage, improve the vital activities of healthy microflora. Papain ferment comprising the framework ensures complete digestion during the period of intestine population by the bacteria promoting their best colonization rate and activation.

The application of careful technological production parameters (low humidity and no active aeration) ensure high safety of the active materials of biologically active components. The stability of the ascorbic acid is $100 \%$.

To establish the prescribed indicators of quality, time and regimes of distribution, we have carried out organoleptic, physicochemical and microbiological studies during production and storage.

The product was stored for 15 months at the temperature not higher than $25^{\circ} \mathrm{C}$ and relative air humidity of $70 \%$.

After the test period, we determined the shape, look, color, taste, odor, average mass of one candy, mass fractions of moist and ascorbic acid, content of bifido- and lactobactera, number of mesophile aerobic and facultatively anaerobic microorganisms, coliforms, pathogenic microorganisms, including salmonella, yeast fungi and moulds. Among toxic elements we studied the presence of lead, arsenic, cadmium, mercury, investigated the level of radionuclides: cesium-137 and strontium-90.

The results of the studies allowed establishing the regulated quality indicators for the developed products (Tables 2 and 3). 
TABLE 2. REGULATED ORGANOLEPTIC INDICATORS OF PROBIOTIC CANDIES

\begin{tabular}{|l|l|}
\hline Name of indicator & \multicolumn{1}{|c|}{ Content } \\
\hline Taste and odor & Clear, typical for this product, no foreign taste of smell \\
\hline Color & $\begin{array}{l}\text { Color corresponds with the formula with dark } \\
\text { inclusions }\end{array}$ \\
\hline Look & Surface is smooth, glossy \\
\hline Notch & $\begin{array}{l}\text { Round, double radius, covered by maltitol Tableted } \\
\text { shell }\end{array}$ \\
\hline $\begin{array}{l}\text { Number of products } \\
\text { with defects in terms } \\
\text { of look and color, } \\
\text { mass \%, not more } \\
\text { than }\end{array}$ & 2.0 \\
\hline
\end{tabular}

The criteria of physicochemical indicators were determined: average mass of a candy, g - $1.00 \pm 10 \%$; Moist mass fraction, $\%$, not more than - 6.5.

TABLE 3. INDICATORS OF NUTRITIONAL VALUE OF PROBIOTIC CANDIES

\begin{tabular}{|c|c|}
\hline Indicator & Value \\
\hline Mass fraction of ascorbic acid, mg/100g & 900 \\
\hline $\begin{array}{c}\text { Content of bifidobacteria (bifidobacterium } \\
\text { adolescentis) (for Bifidopan candies) } \\
\text { CFU/100 g, at least }\end{array}$ & $5.0 * 10^{9}$ \\
\hline $\begin{array}{c}\text { Content of lactobacteria (lactobacillus plantarum } \\
\text { and lactobacillus acidophilus) (for Lactopan } \\
\text { candies) CFU/100 g, at least }\end{array}$ & 20.5 \\
\hline Fats, g/100 g (average) & 67.3 \\
\hline Carbohydrates, g/100 g (average) & 454 \\
\hline Energy value, kcal & \\
\hline
\end{tabular}

It was shown that the bifidobacteria accelerate the digestion of proteins, carbohydrates and fats. They decompose coarse vegetable fibers, take part in the synthesis and absorption of vitamins $\mathrm{B}$ and $\mathrm{K}$, folic and nicotinic acid, increase the activity of lysozyme, promote the synthesis of essential aminoacids, decrease of permeability of tissue barriers from toxic products of pathogenic organisms. Lactobacteria can produce antibacterial substances that prevent the development and kill pathogenic microorganisms. Bifido- and lactobacteria take active participation in digestion and absorption, stimulate intestinal motility. Ascorbic acid having antioxidative properties augments functional properties of eubiotics [1, 9$15]$.

We have also studied the indicators of the safety of developed products, which results has shown compliance of studied criteria to the requirements of the regulations [9].
Sanitary, hygienic and toxicological safety of the products after 15-months storage allowed determining the expiration date (1 year) with necessary safety time of 3 months.

Clinical investigation of the usage effectiveness of the biologically active additive (BAA) with lacto- and bifidobactera for treating patients with dysbacteriosis of 2 nd degree. The test involved 30 volunteers. The BAA with a complex of bifido- and lactobacteria in the amount of: $1 * 10^{8}$ $\mathrm{CFU} / \mathrm{g}$ of Bifidum adolescentis and $1 * 10^{8} \mathrm{CFU} / \mathrm{g}$ of Lactobacillus plantarum variety $377 \mathrm{D}$, Lactobacillus acidophilus variety 6 and variety 100 ASh (not less than) was included into the diet of patients 1 capsule twice a day with food during 14 days. It was demonstrated that taking the biologically active complex provided growth of healthy microorganisms in the intestine and repaired damaged microflora. Before taking the BAA, the contenf ot bifido- and lactobacteria was correspondingly $10^{4}, 10^{5}$ and less than $10^{6} \mathrm{CFU} / \mathrm{g}$, which is lower than normal values. After taking the complex, the amount of necessary symbionts reached normal values, $10^{8}$ and more.

BAA reduced the number of opportunistic microorganisms and eliminated pathogenic microorganism in the gastrointestinal tract-coliform bacterium with haemolysing properties and Candida fungi. Also, positive changes to immune status were established that were accompanied by normalized level of blood immunoglobulines and testified the timely reaction of immune system to foreign substances.

The expert report was made that the implementation of dietotherapy leads to relief of clinical signs of dysbacteriosis: meteorism, stomach ache stopped, stool normalized. In addition, the immunomodulating effect is noted, as well as positive dynamics of digestion indicators with restoration of normal composition of gut microflora.

Actual tests were performed in the department of internal diseases of Siberian State Medical University and Tomsk Regional Clinical Hospital in collaboration with ArtLife Company (Tomsk).

The recommendations for application of probiotic candies were elaborated with due consideration of their consumption level and norms of physiological needs for nutrients for certain social groups.

Recommended consumption rate for children from 3 to 11 years old is 2-3 candies a day;

from 11 to 14 years old 3-4 candies a day; from 14 to 18 years old and adults 3-5 candies a day, which amounts to 30 $50 \%$ of daily norm of vitamin $\mathrm{C}$, bifido- and lactobacteria.

Obtained data allow positioning the candies as a special product with target functional properties as an additional source of bifido- and lactobacteria and vitamin $\mathrm{C}$.

The formulation and technology of the products were tested under conditions of production certified within the international requirements such as ISO 9001, 22000 and GMP rules. 
TABLE 4. RECOMMENDED CONSUMPTION RATE, PCS/DAY

\begin{tabular}{|c|c|c|c|c|c|c|}
\hline $\begin{array}{l}\text { Name of enriched } \\
\text { component }\end{array}$ & Age group & $\begin{array}{l}\text { Consumption } \\
\text { norms [CFU] }\end{array}$ & $\begin{array}{c}30-50 \% \text { of norm, } \\
\text { CFU }\end{array}$ & $\begin{array}{c}\text { Content in } 1 \\
\text { candy } \\
\text { CFU }\end{array}$ & $\begin{array}{c}\text { No. of } \\
\text { candies [pes] }\end{array}$ & $\begin{array}{c}\text { Range of } \\
\text { application }[\mathrm{CFU}]\end{array}$ \\
\hline \multirow[t]{5}{*}{ Bifidobacteria } & from 3 to 7 y.o. & \multirow[t]{5}{*}{$5 * 10^{8}$} & \multirow[t]{5}{*}{$1.5^{*} 10^{8}-2.5^{*} 10^{8}$} & \multirow[t]{5}{*}{$5.0 * 10^{7}$} & $2-3$ & $1.0-1.5^{*} 10^{8}$ \\
\hline & from 7 to 11 y.o. & & & & $2-3$ & $1.0-1.5 * 10^{8}$ \\
\hline & from 11 to 14 y.o. & & & & $3-4$ & $1.5-2.0 * 10^{8}$ \\
\hline & from 14 to 18 y.o. & & & & $3-5$ & $1.5-2.5^{*} 10^{8}$ \\
\hline & adults & & & & $3-5$ & $1.5-2.5^{*} 10^{8}$ \\
\hline \multirow[t]{5}{*}{ Lactobacteria } & from 3 to 7 y.o. & \multirow[t]{5}{*}{$5 * 10^{7}$} & \multirow[t]{5}{*}{$1.5^{*} 10^{7}-2.5^{*} 10^{7}$} & \multirow[t]{5}{*}{$5.0 * 10^{6}$} & $2-3$ & $1.0-1.5^{*} 10^{7}$ \\
\hline & from 7 to 11 y.o. & & & & $2-3$ & $1.0-1.5^{*} 10^{7}$ \\
\hline & from 11 to 14 y.o. & & & & $3-4$ & $1.5-2.0^{*} 10^{7}$ \\
\hline & from 14 to 18 y.o. & & & & $3-5$ & $1.5-2.5 * 10^{7}$ \\
\hline & adults & & & & $3-5$ & $1.5-2.5^{*} 10^{7}$ \\
\hline
\end{tabular}

\section{References}

[1] A.N. Avstrievskikh, A.A. Vekovtsev, V.M. Poznyakovskiy, "Products of a healthy man: new technologies, quality assurance, application efficiency", monograph (in Russian), Novosibirsk: Sib. Univ. Press, 2005, p. 416.

[2] Second action plan in food products and nutrition for European region of WHO for 2007-2012 (in Russian), Copenhagen: European regional bureau of WHO, 2007, p. 24, Retrieved from: http:/ http://www.euro.who.int/document/rc57/rdoc10.pdf.

[3] N.F. Gerasimenko, V.M. Poznyakovskiy, N.G. Chelnakova, "Methodological aspects of complex safe nutrition: importance for preservation of health and working efficiency" (in Russian), Human. Sport. Medicine, 2017, No. 1, Vol. 17, p. 79.

[4] World Health Organization, "Report on situation in the field of noncontagious diseases in the world" (in Russian), 2010 executive summary, Geneve: WHO, 2011, p. 21.

[5] Health of Russia: Atlas (in Russian) L. A. Bokeriya, Ed. Moscow:NTsSSHk named after A. N. Bakulev RAMS, Vol. 8, 2012, p. 86.

[6] I.P. Pavlov, "Complete collected works. Nobel award speech on December 12, 1904 in Stockholm”, Vol. 2, Moscow; Leningrad: issued by AN USSR, 1951, pp. 347-366.

[7] V.M. Poznyakovskiy, O.V. Chugunova, M.Yu. Tamova, "Food ingredients in biologically active additions" (in Russian), Moscow: INFRA-M, 2017, p. 143.
[8] V.B. Spirichev, L.N. Shatnyuk, V.M. Pozniakovskiy; edited by V.B. Spirichev, "Enrichment of food products by vitamins and mineral substances" (in Russian), Science and Technology, 2nd issue, Novosibirsk: SIb. Univ. Press, 2005, p. 548.

[9] "On safety of certain special food products, including dietic, treatment and protective diet" (in Russian), Technical regulations TS027/2012.

[10] V.A. Aleshkin, A.M. Amerhanova, V.V. Pospelova, S.S. Afanasiev, B.A. Shenderov, "History, present situation, and prospects of probiotic research conducted in the G.N.Gabrichevsky Institute for Epidemiology and Microbiology", Microbial ecology in Yealth and Disease, 2008, pp. $113-115$.

[11] G.R. Gibson, H.M. Probert, J.A.E. Van Loo, M.B. Roberfroid, "Dietary odulation of the human colonic microbiota: Updating the concept of prebiotics:",Nutr. Res. Rev, 2004, No. 17, p. 257-259.

[12] C. Martin, W. Walker, "Probiotics: Role in Pathophysiology and Prevention in Necrotizing Enterocolitis", Probiotics and NEC, 2008, No. 32, pp. 127-137.

[13] A. Mortazavian, S. N. Razavi, M. R. Ehsani, S. Sohrabvandi, "Principles and methods of microencapsulation of probiotic microorganisms", Iranian J. of Biotechnology, 2007, Vol. 5, № 1, pp. 3-22.

[14] G. Tannock, "The search for disease-associated compositional shifts in bowel bacterial communities of humans", Trends in Microbiology, 2005, Vol. 16, No.10, pp. 488-495

[15] G. Tannock, "What immunologists should know about bacterial communities of the human bowel", Seminars in Immunology, 2007, Vol. 19, No. 2, pp. 94-105. 